\title{
La Causalidad de Estar en China
}

\author{
Edwin Trejo
}

Perú

Hace un poco más de 3 años llegué a China para estudiar mi maestría, pero el comienzo de todo esto fue ciertamente una casualidad. A inicios del año 2015, mi madre me animó a estudiar el idioma chino que poco a poco me fue interesando más por su cultura y una escritura totalmente distinta al que estamos acostumbrados. Es así como a través de un portal de noticias vía web me enteré de una convocatoria de becas para estudiar en China. Sin pensarlo mucho, decidí probar suerte y en menos de 1 mes me llegó la noticia que fui aceptado para dicha beca otorgado por el gobierno chino. Todo fue tan repentino que tuve que avisar a mi familia que en 2 semanas viajaría a China para estudiar mi postgrado.

No recuerdo bien mis sentimientos de ese entonces, quizás un poco de temor por conocer un nuevo país tan lejano, difícil de imaginar, pero también con mucho entusiasmo de aprender y ganar experiencias únicas en mi vida. Al llegar a Beijing, me esperaba un estudiante voluntario de la universidad quien me ayudó en todo e incluso me invitó a cenar. Con ello, me di cuenta de que los chinos son muy solidarios, no importa si hay problemas de comunicación por el idioma ya que ellos siempre trataran de ayudarte en lo que puedan (Fan, 2000).

Adaptarme a esta nueva sociedad no fue fácil, sin embargo, tampoco diría que fue difícil. Poco a poco fui encontrando amigos yotros compatriotas que también estudiaban en mi universidad, lo cual fue una sorpresa, puesto que no contaba con la idea de encontrarlos al llegar. Además, tuve la suerte de encontrar a un excelente supervisor que me apoyó en absolutamente todo lo académico. Mientras llevaba los cursos, en las vacaciones iba a conocer otras ciudades de China. Y hasta el día de hoy puedo decir que he conocido más ciudades que un propio chino, más de 14 ciudades y 10 provincias llenas de vivencias, paisajes e historia. Parecería que ya conozco toda China, pero la verdad es que aún me falta probablemente la mitad de este país. Así de grande es este territorio ancestral.

Existen 3 motivos primordiales por los cuales considero a China como un país de grandes desarrollos. En primer lugar, la integracióndel sistema de pago en un solo dispositivo como el celular (Klein, 2019). La facilidad de poder comprar, vender y pagar todo lo que te puedas imaginar es inalcanzable. Desde comprar comida, pagar el metro, alquilar bicicletas, hasta hacer pagos por servicios de agua y luz, hacer transacciones de dinero, comprar boletos de avión y trenes, compras de seguro de todo tipo y si continuo la lista no acabaría. Wechat y Alipay son las grandes compañías que dominan 


\section{JOURNAL OF LATIN AMERICAN SCIENCES AND CULTURE}

Vol. 2 - 2020

Universidad Privada del Valle - Bolivia

https://doi.org/10.52428/2788891.v2i2.52

este negocio ya consolidado por ellos, pues absolutamente todos tienen estas aplicaciones instaladas en sus celulares.

En segundo lugar, la seguridad de caminar libremente por las calles a cualquier hora del día y la noche sin tener que estar atento al peligro es tranquilizante (Hebenton \& Jou, 2010). Raras veces verás a dos personas discutiendo a golpes o robos callejeros o asaltos. Aquí las leyes sí se hacen respetar y la seguridad cibernética también ha contribuido últimamente con ello.

Y finalmente, está el desarrollo tecnológico que avanza a pasos agigantados. Actualmente, el asentamiento del IoT (Chen et al., 2014) y el uso de la Inteligencia artificial están marcando unatendencia en todo el mundo. Y me atrevo a decir que aun más en China. Hace poco más de medio año, empecé a trabajar para una empresa que desarrolla productos tecnológicos en distintos mercados como la seguridad, finanzas, edificaciones, salud y transporte.

Me desempeño como Ingeniero de algoritmos y vengo desarrollando investigaciones en criminalística para estimar parámetros de las personas con las huellas del zapato. Diría que, en un inicio, mi experiencia laboral también fue una casualidad, puesto que mis conocimientos de estudios están más ligados a la mecánica y electrónica. No obstante, gracias al desarrollo de mi tesis en la maestría, que fue crear un sistema interactivo para reconocimiento de posiciones de Yoga, me permitió entrar en esta área de especialización y hoy en día sigo aprendiendo más.

Se dice que las casualidades en la vida no existen y que realmente es uno mismo quien la fabrica. Sea como fuese, me alegro de haber adquirido todas esas experiencias y poder compartirlas para que más personas se atrevan a salir de la zona de confort. El miedo a enfrentar nuevas cosas debe ser un impulso para el éxito mas no un impedimento para detenerlas.

\section{REFERENCIAS BIBLIOGRÁFICAS}

Chen, S., Xu, H., Liu, D., Hu, B., \& Wang, H. (2014). A vision of IoT: Applications, challenges, and opportunities with china perspective. IEEE Internet of Things journal, 1(4), 349-359.

Fan, Y. (2000). A classification of Chinese culture. Cross Cultural Management: An International Journal.

Hebenton, B., \& Jou, S. (2010). Criminology in and of China: Discipline and power. Journal of Contemporary Criminal Justice, 26(1), 7-19.

Klein, A. (2019). Is China's new payment system the future. Brookings Institution, June, online at http://www.brookings.edu/wpcontent/iploads/2019/05/ES_20190617_Klein_ChinaPayments.pdf 


\section{JOURNAL OF LATIN AMERICAN SCIENCES AND CULTURE}

Vol. 2 - 2020

Universidad Privada del Valle - Bolivia

https://doi.org/10.52428/2788891.v2i2.52

Fuentes de financiamiento: Esta investigación fue financiada con fondos del autor.

Declaración de conflicto de intereses: El autor declara que no tiene ningún conflicto de interés.

\section{Copyright (c) 2021 Edwin Trejo}

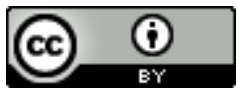

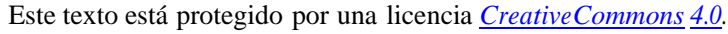

Usted es libre para Compartir — copiar y redistribuir el material en cualquier medio o formato- y Adaptar el documento —remezclar, transformar y crear a partir del material - para cualquier propósito, incluso para fines comerciales, siempre que cumpla la condición de:

Atribución: Usted debe dar crédito a la obra original de manera adecuada, proporcionar un enlace a la licencia, e indicar si se han realizado cambios. Puede hacerlo en cualquier forma razonable, pero no de forma tal que sugiera que tiene el apoyo del licenciante o lo recibe por el uso que hace de la obra. 